\title{
Aprotinin in Orthotopic Liver Transplantation
}

\author{
WOLF OTTO BECHSTEIN, M.D., HANNO RIESS, M.D., \\ GERHARD BLUMHARDT, M.D., GABRIELE HIMMELREICH, M.D., \\ MARIANNE JOCHUM, M.D., HERWIG GERLACH, M.D., \\ ROLF ROSSAINT, M.D., HEINRICH KECK, M.D., and \\ PETER NEUHAUS, M.D.
}

\begin{abstract}
Aprotinin is a protease inhibitor isolated from bovine lungs and other tissues. Its biochemical structure, a single-chain polypeptide of $6,512 \mathrm{kD}$, and biophysical properties are well defined. ${ }^{1}$ The activity of commercial preparations of aprotinin is usually described in kallikrein inactivator units (KIU), 0.1 million KIU being equivalent to $2.15 \mu \mathrm{mol}$ of aprotinin per liter. By inhibiting trypsin, plasmin, plasma kallikrein, and tissue kallikreins in addition to other serine proteases, aprotinin can affect the fibrinolytic and coagulation, complement, and other biologic systems. ${ }^{1}$

Aprotinin has been shown to reduce blood product requirements significantly in cardiac surgery in a welldesigned randomized double-blind trial. ${ }^{2}$ The role of aprotinin in cardiac surgery has been confirmed in several clinical studies, ${ }^{3.4}$ and this substance is now used routinely in many cardiac units in Europe.

Several pathological conditions can be encountered in liver transplant recipients, especially those individuals afflicted with advanced cirrhoses of the liver, which make them particularly vulnerable to increased blood loss. These risk factors include preoperatively decreased synthesis of clotting factors, thrombocytopenia secondary to hypersplenism, occasionally low-grade fibrinolysis associated with endotoxemia, and the surgical risks attributable to portal hypertension with extremely vulner-
\end{abstract}

From the Departments of Surgery, Internal Medicine, and Anesthesiology, University Clinic Rudolf Virchow, Berlin, and the Department of Clinical Chemistry and Biochemistry, University of Munich. Munich, Germany.

Reprint requests: Dr. Bechstein, Dept. of Surgery, University Clinic Rudolf Virchow, Free University of Berlin, Augustenburger Platz 1, 1000 Berlin 65, Germany. able venous collaterals and, sometimes, multiple adhesions because of previous hepatobiliary or portal decompressive surgery. In addition, hyperfibrinolysis is especially pronounced in the late anhepatic phase and immediately after revascularization of the cold-stored graft, as has been shown by a number of studies. ${ }^{5-7}$

The Pittsburgh liver transplant group has shown that the degree of blood usage during orthotopic liver transplantation (OLT) correlates significantly with postoperative mortality during the first half year after the procedure. ${ }^{8}$ Excessive blood loss may lead to prolonged intubation and ventilation, impairment of renal function, and an increased risk of infection. Preventing excessive blood loss during liver transplantation may thus contribute to improvements of the overall results. Because hyperfibrinolysis plays a significant role in liver transplantation, and because aprotinin acts as an antifibrinolytic agent, the potential role of aprotinin in liver transplantation has been investigated.

\section{CLINICAL STUDIES OF APROTININ IN LIVER TRANSPLANTATION}

In the initial report of a potentially beneficial effect of aprotinin in liver transplantation, ${ }^{9}$ the agent was given only as a bolus of 0.5 million KIU during induction of anesthesia, immediately prior to the anhepatic phase, and immediately prior to reperfusion. This low-dose bolus regimen was given instead of the continuous infusion promoted by the cardiac surgery study of Royston et $\mathrm{al}^{2}$ because of fear of a higher risk of subsequent thromboses of vascular anastomoses in the setting of liver transplantation without intraoperative anticoagulation. In the initial study of 10 consecutive primary allografts and 10 
previous historic controls, a significant reduction of blood product requirements following reperfusion of the graft and a significantly shorter operating time from the time of reperfusion until skin closure were noted. ${ }^{9}$ Additionally, the operative field was often observed to be "bone dry" at the end of the procedure, unlike the previously common diffuse oozing from previously dry surfaces. Such an unusually dry surgical field had also been reported by cardiac surgeons using aprotinin, although dryness is an admittedly subjective assessment and difficult to quantify. The results of our initial report were confirmed by the group of Rolles at the Royal Free Hospital, London, England. ${ }^{10-12}$ However, those workers applied aprotinin according to the dosage protocol established by Royston ${ }^{2}$ and associates with the modification of adding 0.07 million KIU of aprotinin to each unit of blood transfused intraoperatively (Table 1). In this retrospective study with historical controls, the investigators found, besides significant reductions in total transfusion requirements, especially in the postanhepatic stage, and a shortening of the operative time in patients receiving aprotinin, a significant reduction of the mean length of the ICU stay and thus concluded that aprotinin treatment implied overall reduction of the costs of liver transplantation.

Because of these initial experiences with aprotinin, our group felt that a properly randomized placebo-controlled trial would submit the patients in the control group to an unjustified risk, and we therefore continued to use aprotinin with careful prospective monitoring for eventual side effects and concomitant analysis of parameters of the coagulation and fibrinolysis systems. Orthotopic liver transplantation was carried out according to estab-

TABLE 1. Dosage Regimens for Aprotinin Application in Orthotopic Liver Transplantation

\begin{tabular}{|c|c|c|}
\hline Reference & $\begin{array}{l}\text { Dose } \\
\text { (million KIU) }\end{array}$ & $\begin{array}{l}\text { Method of } \\
\text { Administration }\end{array}$ \\
\hline \multirow{3}{*}{$\begin{array}{l}\text { Bechstein et al } \\
(1991)^{13}\end{array}$} & 0.5 & Induction bolus \\
\hline & 0.5 & Anhepatic bolus \\
\hline & 0.5 & Reperfusion bolus \\
\hline Grosse et al $(1991)^{17}$ & 2.0 & Induction bolus \\
\hline $\begin{array}{l}\text { Groh et al (1992) } \\
\text { (Royston et al 1987) }^{2}\end{array}$ & $0.5 /$ hour & Continuous infusion \\
\hline \multirow[t]{2}{*}{ Mallett et al $(1991)^{12}$} & $\begin{array}{l}2.0 \\
0.5 / \text { hour }\end{array}$ & $\begin{array}{l}\text { Induction bolus } \\
\text { Continuous infusion }\end{array}$ \\
\hline & 0.07 & Per unit of RBC \\
\hline \multirow{3}{*}{$\begin{array}{l}\text { Himmelrich et al } \\
(1992)^{18}\end{array}$} & $0.2 /$ hour & Induction infusion \\
\hline & $0.4 /$ hour & Anhepatic infusion \\
\hline & $0.1 /$ hour & Skin closure postop. day 3 \\
\hline
\end{tabular}

lished surgical techniques with routine use of a venovenous (portofemoral-axillary) bypass driven by a centrifugal pump (Biomedicus, Minnetonka, MN). Substitution of packed red blood cells (RBC) was aimed at maintaining a hemoglobin concentration $>10 \mathrm{mg} / \mathrm{dl}$. With each unit of RBC, one unit of fresh frozen plasma (FFP) was usually administered except in patients with severe ascites, who received additional units of FFP to compensate for their massive protein loss. Whole blood, fresh whole blood, or platelets were not given. The Cell Saver for autologous blood transfusion or a rapid infusion pump were never used. ${ }^{13}$

In 46 consecutive patients receiving primary liver grafts according to this protocol, and with bolus administration of aprotinin (see above), the mean transfusion requirements were $7.5 \pm 4.6$ units of $\mathrm{RBC}$ and $9.1 \pm 6.7$ units of FFP. These reductions of homologous blood product requirements were not statistically significantly different from that of the initial historical control group $(9.7 \pm 5.5$ units of RBC and $10.4 \pm 6.2$ units of FFP). However, our experience compared very favorably with previous reports on blood product usage in OLT (Table 2). ${ }^{8,14-16}$ Furthermore, in 10 patients who received aprotinin, detailed analyses of the coagulation and fibrinolysis system were carried out. ${ }^{7}$ Aprotinin did not prevent the increase of tissue plasminogen activator ( $t$ PA) activity during the anhepatic phase, but the maximal values of t-PA activity were lower than those reported by other investigators who did not use aprotinin intraoperatively. ${ }^{5}$ Using the aprotinin dosage recommended by Royston and associates ${ }^{2}$ (Table 1), Grosse et al $^{17}$ reported a $50 \%$ reduction of mean homologous blood product requirements in a prospective study of 25 consecutive patients compared with 25 historical controls. The t-PA activity levels were significantly lower at the time of reperfusion of the graft than in the control group (see also the article by Grosse et al in this issue).

Because other investigators had not observed higher risk of thrombosis at vascular anastomoses using highdose aprotinin as in cardiac surgery, we carried out a

TABLE 2. Intraoperative Blood Product Requirements in Orthotopic Liver Transplantation*

\begin{tabular}{llc}
\hline \hline Reference & $\begin{array}{l}\text { Units } \\
\text { of RBC }\end{array}$ & $\begin{array}{l}\text { Units } \\
\text { of FFP }\end{array}$ \\
\hline Bontempo et al, Pittsburgh $(1985)^{8}$ & 42.8 & 39.9 \\
Lewis et al, Pittsburgh $(1987)^{14}$ & 27.0 & 26.0 \\
Farrar et al, St. Louis $(1988)^{15}$ & 22.0 & 38.2 \\
Chapin et al, Omaha $(1989)^{16}$ & 14.3 & 16.4 \\
$\begin{array}{l}\text { Bechstein et al, Berlin (1991) } \\
\text { (with aprotinin) }\end{array}$ & 7.6 & 9.1 \\
\hline * First OLT in adults, mean values. & & \\
\end{tabular}

*First OLT in adults, mean values. 
TABLE 3. Aprotinin Application (Million KIU) in Randomized Trial

\begin{tabular}{lll}
\hline \hline $\begin{array}{l}\text { Bolus } \\
(n=13)\end{array}$ & Time & $\begin{array}{l}\text { Infusion } \\
(n=10)\end{array}$ \\
\hline 0.5 & Induction of anesthesia & $0.2 /$ hour \\
0.5 & Anhepatic phase & $0.4 /$ hour \\
0.5 & $\begin{array}{l}\text { Reperfusion } \\
\text { Skin closure (heparin 250 IU/h; } \\
\text { heparin 500 IU/h starting 12 h } \\
\text { postop; postop. day 3) }\end{array}$ & $0.1 /$ hour \\
\hline
\end{tabular}

Because other investigators had not observed higher risk of thrombosis at vascular anastomoses using highdose aprotinin as in cardiac surgery, we carried out a randomized controlled trial comparing our aprotinin bolus regimen ( $n=13$; Group 1$)$ with a continuous intravenous infusion protocol $\left(\mathrm{n}=10\right.$; Group 2 ) $($ Table 3$) .^{18}$ With continuous infusion, constantly and significantly higher systemic aprotinin concentrations could be obtained even during the preanhepatic phase and throughout the entire procedure compared with bolus application (Fig. 1). There was a trend toward lower transfusion requirements in Group 2; however, it reached statistical significance for RBC usage only within the first 3 postoperative days (Table 4). Nine of the patients in Group 2 showed no signs of hyperfibrinolysis as defined by readings from the thrombelastogram, and only one patient developed severe hyperfibrinolysis. In comparison, 3
TABLE 4. Blood Product Requirements (Median, Range) in Randomized Trial Comparing Aprotinin Bolus Treatment (Group 1) with Continuous Aprotinin Infusion (Group 2)

\begin{tabular}{lcll}
\hline \hline & $\begin{array}{l}\text { Group } ~ \\
(n=13)\end{array}$ & $\begin{array}{l}\text { Group 2 } \\
(n=10)\end{array}$ & $p$ Value \\
\hline RBC intraop. & $8(4-26)$ & $7(2-20)$ & NS \\
FFP intraop. & $10.5(7-35)$ & $8(2-28)$ & NS \\
RBC postop. day 3 & $3.5(0-9)$ & $1.5(0-6)$ & $<0.05$ \\
FFP postop. day 3 & $9.5(4-22)$ & $6.5(0-17)$ & NS \\
\hline
\end{tabular}

and 4 of 13 patients from Group 1 showed mild hyperfibrinolysis and severe hyperfibrinolysis, respectively (Table 5).

In contrast to these results, the only placebo-controlled, randomized study of aprotinin in liver transplantation with a dosing scheme according to Royston and associates, ${ }^{2}$ carried out by the Munich group, could not confirm a beneficial effect of aprotinin with regard to blood product requirements or other of the aforementioned criteria. ${ }^{19}$ The aprotinin group needed 18 units of RBC, whereas the control group needed 20 units (NS).

The various aprotinin dosage schemes employed during OLT and published to date are summarized above in Table 1. More meaningful may be a comparison of the total estimated aprotinin dose used intraoperatively by various investigators together with the mean transfusion requirements (Table 6) or the aprotinin plasma levels

\section{INTRA-/POSTOPERATIVE APROTININ LEVELS Boli versus Infusion}

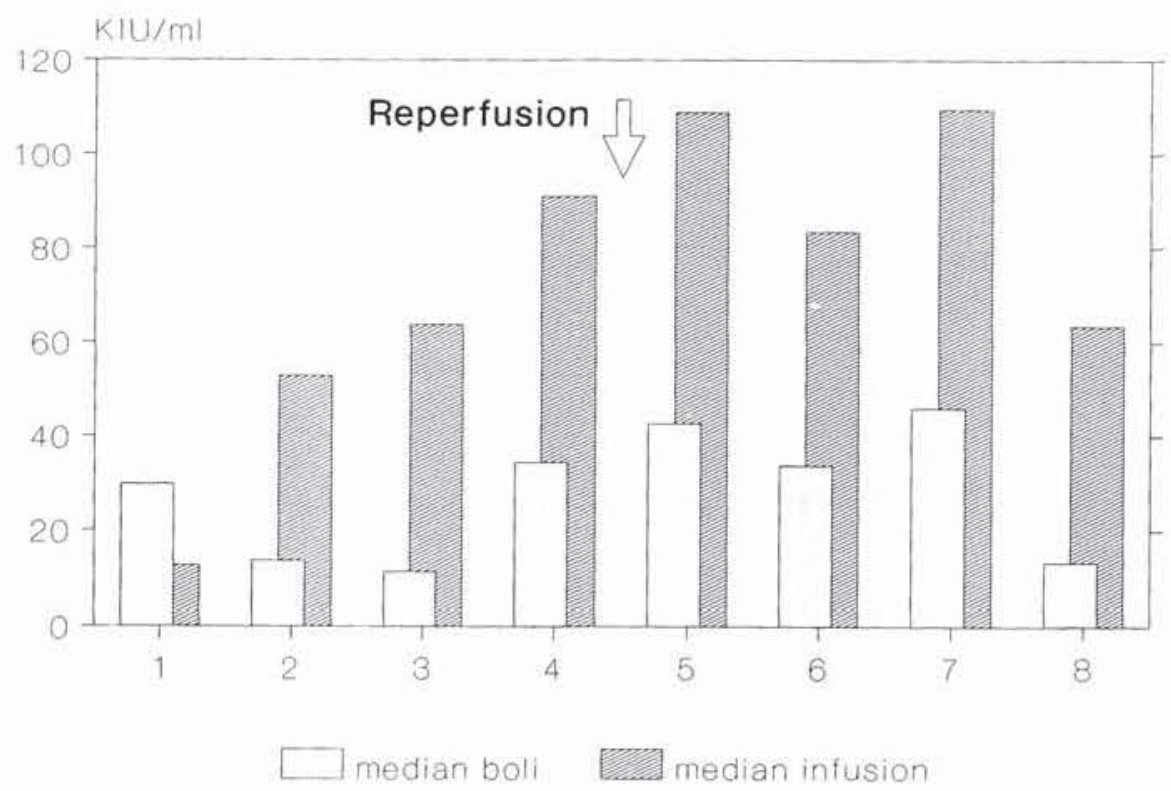

FIG. 1. Serum Aprotinin Concentrations According to Method of Administration. Time $1=$ after induction of anesthesia; $2=5$ minutes before anhepatic phase: $3=10$ minutes after beginning of anhepatic phase; $4=5$ minutes before reperfusion; $5=5$ minutes after reperfusion; $6=15 \mathrm{~min}$ utes after reperfusion; $7=1$ hour after reperfusion; $8=12$ hours after reperfusion. 
TABLE 5. Incidence and Severity of Hyperfibrinolysis during OLT with Bolus vs Continuous Infusion Application of Aprotinin

\begin{tabular}{lll}
\hline \hline $\begin{array}{l}\text { Severity of } \\
\text { Hyperfibrinolysis }\end{array}$ & $\begin{array}{l}\text { Bolus } \\
(n=13)\end{array}$ & $\begin{array}{l}\text { Infusion } \\
(n=10)\end{array}$ \\
\hline $\begin{array}{l}\text { None } \\
\quad\left(\text { WBLT }^{*}>120 \mathrm{~min}\right)\end{array}$ & 6 & 9 \\
$\begin{array}{l}\text { Mild } \\
\quad\left(\text { WBLT }^{*} 90-120\right)\end{array}$ & 3 & 0 \\
$\begin{array}{l}\text { Severe } \\
(\text { WBLT }\end{array}$ & $490 \mathrm{~min})$ & 1 \\
\hline
\end{tabular}

*WBLT $=$ whole blood clot lysis time as measured by thrombelastogram.

transfusion requirements of 18 units of RBC. These differences are difficult to explain other than by speculating that on the one hand, the meticulous blood component therapy employed by the Munich group, which varies from the practice of most other transplant centers, ${ }^{20}$ counteracted potential effects of aprotinin, and that on the other hand, differences in the selection and perioperative management of the patients led to greater transfusion requirements.

\section{POSSIBLE MECHANISMS OF ACTION OF APROTININ ON HEMOSTASIS DURING OLT}

Thorough investigations of hemostasis in our patients suggest that aprotinin bolus therapy led to smaller

TABLE 6. Blood Product Requirements and Total Estimated Aprotinin Dose in Clinical Studies during Orthotopic Liver Transplantation

\begin{tabular}{|c|c|c|c|}
\hline \multirow[b]{2}{*}{ Reference } & \multicolumn{2}{|c|}{ Mean $R B C$} & \multirow{2}{*}{$\begin{array}{c}\text { Total } \\
\text { Aprotinin } \\
\text { Dose } \\
\text { (million KIU)* }^{*}\end{array}$} \\
\hline & $\begin{array}{l}\text { Treatment } \\
\text { Group }\end{array}$ & $\begin{array}{l}\text { Control } \\
\text { Group }\end{array}$ & \\
\hline Bechstein et al ${ }^{13}(1991) \dagger$ & 7.5 & 9.7 & 1.5 \\
\hline Grosse et al ${ }^{17}(1991) \dagger$ & 8.1 & 23.3 & 5.0 \\
\hline Mallett et al ${ }^{12}(1991) \dagger$ & 7.5 & 23.6 & 5.6 \\
\hline Groh et al ${ }^{19}(1992) \ddagger$ & 18.0 & 20.0 & 5.0 \\
\hline Himmelreich et al ${ }^{18}(1992) \S$ & 7.0 & 8.0 & 2.0 \\
\hline
\end{tabular}

*Calculated assuming a 6-hour operation with substitution of 8 units of RBC.

$\dagger$ Historical controls.

$\ddagger$ Randomized placebo-controlled study.

$\S$ Randomized study of bolus vs continuous infusion of aprotinin (median values).
TABLE 7. Hemostatic Parameters in Perfusate (Median, Range) from Aprotinin Bolus

Treatment (Group 1) and Continuous Aprotinin Infusion (Group 2)

\begin{tabular}{lcccc}
\hline \hline & $\begin{array}{l}\text { Group I } \\
(N=13)\end{array}$ & $\begin{array}{l}\text { Group 2 } \\
(N=10)\end{array}$ & $p$ Value \\
\hline t-PA activity (IU) & $12(0.7-23.6)$ & 5 & $(0.7-17.4)$ & 0.101 \\
t-PA antigen (ng/ml) & $12.3(7.2-26.6)$ & $10.1(1.2-19.3)$ & 0.050 \\
PAI activity (AU) & $6.4(0-22)$ & $17.8(8.8-30.4)$ & 0.043 \\
$\alpha_{2}$-Antiplasmin (\%) & $63 \quad(5-95)$ & $93(68-102)$ & 0.010 \\
\hline
\end{tabular}

increases of profibrinolytic parameters than in the experience of other groups. ${ }^{7}$ In a randomized controlled study of four patients in each group, comparing standard treatment with aprotinin infusion according to the Royston protocol, Cottam et al ${ }^{21.22}$ showed that t-PA levels were significantly lower in the aprotinin-treated patients at the end of the anhepatic phase, a finding similar to that observed in the study of Grosse et al $^{17}$ (see above). Furthermore, Cottam and associates reported significantly higher levels of $\alpha_{2}$-antiplasmin during all stages of liver transplantation following administration of aprotinin. They therefore hypothesized that aprotinin reduces t-PA production by inhibiting kallikrein and that aprotinin's known antiplasmin effect might neutralize plasmin formed by t-PA or kallikrein. ${ }^{21.22}$

The antifibrinolytic effect of aprotinin has also been demonstrated in an in vitro study by treating blood samples obtained during OLT with aprotinin before performing thromboelastography. ${ }^{23}$

The graft itself may play an important role in the development of hyperfibrinolysis after reperfusion. This has been evident clinically through the observation that oozing becomes apparent exclusively after revascularization and has to be expected especially when using grafts with severe ischemic damage or primary nonfunction. Besides monitoring the systemic levels of coagulation and fibrinolysis factors, we wondered whether the graft itself might release activators of fibrinolysis. Therefore, blood passing through the liver immediately after reperfusion and collected by venting the inferior vena cava was collected and analyzed. ${ }^{18.24}$ In the previously mentioned randomized comparison of 13 patients receiving aprotinin bolus therapy with 10 patients receiving continuous aprotinin infusion, t-PA antigen and activity were lower, whereas PAI and $\alpha_{2}$-antiplasmin activities were higher in the perfusate collected from patients of the infusion group (Table 7). These results may be explained by the hypothesis that higher aprotinin levels will reduce endothelial damage in the liver graft during reperfusion. 


\section{EFFECTS OF APROTININ ON GRAFT PRESERVATION}

Lie et $\mathrm{al}^{25}$ first described a protective effect of aprotinin against ischemic hepatocellular damage both in models of warm hepatic ischemia induced by clamping of the hepatoduodenal ligament in normal and cirrhotic rats and in cold ischemia in a model of OLT in rats by pretreating the liver donors with aprotinin. However, the results could not be confirmed in the isolated perfused rat liver model. ${ }^{26}$ On the other hand, a large-animal study involving OLT in pigs demonstrated that treating the recipients with a continuous intravenous infusion of aprotinin resulted both in significantly less hepatocellular ischemic damage, as reflected by postoperative serum levels of markers of liver cell integrity (SGOT), and significantly prolonged survival in comparison to controls. ${ }^{27}$ These latter studies underscore a potential role of aprotinin in the prevention of reperfusion injury rather than effects during cold storage, as only the liver recipients were treated.

\section{ADVERSE EFFECTS OF APROTININ}

Because aprotinin is of bovine origin, anaphylactoid reactions may be observed, as with any other foreign protein, especially during repeated exposure after potential antibody formation. Although we have never encountered such reactions in more than 300 liver transplantations using aprotinin, not even after repeated administration (e.g., in the setting of retransplantation of the liver), severe anaphylactoid reactions have been reported. In a study involving more than 150 patients undergoing cardiac surgery, one single case of severe hypotension thought to be attributable to aprotinin has been reported. ${ }^{4}$ Recently, such anaphylactic reactions were shown to be $\mathrm{IgF}$ mediated. ${ }^{28}$ It therefore seems advisable to obtain a medical history of possible previous aprotinin exposure before treatment and to be prepared for appropriate management of any anaphylactoid reactions. Antihistamine receptor drugs can be administered during induction of anesthesia and before aprotinin administration; intraoperative use of steroids is part of the protocol in most transplant centers and would also counteract anaphylactoid reactions.

\section{CONCLUSION}

A number of clinical studies have now shown a reduction of blood product requirements and decreased tendencies for fibrinolysis, especially during the anhe- patic and early reperfusion phase of OLT, when aprotinin is administered intraoperatively. However, a large randomized trial with sufficient numbers of patients and, preferably, a multicenter design is still lacking to confirm the protective effects of aprotinin and the optimal dose beyond any doubt.

\section{REFERENCES}

1. Verstraete M: Clinical applications of inhibitors of fibrinolysis. Drugs 29:236-261, 1985.

2. Royston D, BP Bidstrup, KM Taylor, RN Sapsford: Effect of aprotinin on need for blood transfusion after repeat open hear surgery. Lancet 2:1289-1291, 1987.

3. Fraedrich G, C Weber, C Bernard, A Hettwer, V Schlosser: Reduction of blood transfusion requirement in open heart surgery by administration of high doses of aprotinin. Preliminary results. Thorac Cardiovasc Surg 37:89-91, 1989.

4. Dietrich W, A Barankay, G Dilthey, R Henze, E Niekau, F Sebening, JA Richter: Reduction of homologous blood requirement in cardiac surgery by intraoperative aprotinin application. Clinical experience in 152 cardiac surgical patients. Thorac Cardiovasc Surg 37:92-98, 1989.

5. Porte RJ, FA Bontempo, EAR Knot, JH Lewis, YG Kang, TE Starzl: Systemic effects of tissue plasminogen activator-associated fibrinolysis and its relation to thrombin generation in orthotopic liver transplantation. Transplantation 48:978-984, 1989

6. Harper PL, RJ Luddington, I Jennings, D Reardon, MJ Seaman, RW Carrell, JR Klink, M Smith, K Rolles, R Calne: Coagulation changes following hepatic revascularization during liver transplantation. Transplantation 48:603-607, 1989.

7. Himmelreich G, B Kierzek, P Neuhaus, KJ Slama, H Riess: Fibrinolytic changes and the influence of the early perfusate in orthotopic liver transplantation with intraoperative aprotinin treatment. Transplant Proc 23:1936-1937, 1991.

8. Bontempo FA, JH Lewis, DH Van Thiel, JA Spero, MV Ragni, P Butler, L Israel, TE Starzl: The relation of preoperative coagulation findings to diagnosis, blood usage, and survival in adult liver transplantation. Transplantation 39:532-536, 1985.

9. Neuhaus P, WO Bechstein, B Lefebre, G Blumhardt, K Slama: Effect of aprotinin on intraoperative bleeding and fibrinolysis in liver transplantation. Lancet 2:924-925, 1989.

10. Mallett SV, D Cox, AK Burroughs, K Rolles: Aprotinin and reduction of blood loss and transfusion requirements in orthotopic liver transplantation. Lancet 336:886-887, 1990.

11. Mallett S, K Rolles, D Cox, A Burroughs, B Hunt: Intraoperative use of aprotinin (Trasylol) in orthotopic liver transplantation. Transplant Proc 23:1931-1932, 1991.

12. Mallett SV, D Cox, AK Burroughs, K Rolles: The intra-operative use of Trasylol (aprotinin) in liver transplantation. Transplant Int 4:227-230, 1991.

13. Bechstein WO, H Riess, P Neuhaus, G Himmelreich, R Steffen KJ Slama, R Rossaint, G Blumhardt: The effect of aprotinin on blood product requirements during orthotopic liver transplantation. Clin Transplant 5:422-426, 1991.

14. Lewis JH, FA Bontempo, F Cornell, JE Kiss, P Larson, MV Ragni, EO Rice, JA Spero, TE Starzl: Blood use in liver transplantation. Transfusion 27:222-225, 1987

15. Farrar RP, DW Hanto, MW Flye, H Chaplin: Blood component use in orthotopic liver transplantation. Transfusion 28:474 478, 1988.

16. Chapin JW, MC Newland, BJ Hurlbert: Anesthesia for liver transplantation. Semin Liver Dis 9:195-201, 1989. 
17. Grosse H, W Lobbes, M Frambach, O von Broen, B Ringe, M Barthels: The use of high dose aprotinin in liver transplantations. The influence on fibrinolysis and blood loss. Thromb Res 63:287297, 1991.

18. Himmelreich G, M Muser, P Neuhaus, WO Bechstein, KJ Slama, M Jochum, H Riess: Different aprotinin applications influencing hemostatic changes in orthotopic liver transplantation. Transplantation 53:132-136, 1992.

19. Groh J, M Welte, SC Azad, H Forst, E Pratschke, MAA Kratzer: Does aprotinin affect blood loss in liver transplantation? Lancet $340: 173,1992$.

20. Kratzer M, J Dietrich, H Denecke, M Knedel: Hemostatic variables and blood loss during orthotopic human liver transplantation. Transplant Proc 23:1906-1911, 1991.

21. Hunt BJ, S Cottam, H Segal, R Ginsburg, D Potter: Inhibition by aprotinin of tPA-mediated fibrinolysis during orthotopic liver transplantation. Lancet 336:381, 1990.

22. Cottam S, B Hunt, H Segal, R Ginsburg, D Potter: Aprotinin inhibits tissue plasminogen activator-mediated fibrinolysis during orthotopic liver transplantation. Transplant Proc 23:1933, 1991.
23. Kang Y, AM de Wolf, S Aggarwal, E Campbell, LK Martin: In vitro study of the effects of aprotinin on coagulation during orthotopic liver transplantation. Transplant Proc 23:1934-1935, 1991.

24. Riess H, M Jochum, W Machleidt, G Himmelreich, KJ Slama, R Steffen: Possible role of the phagocytic proteinases cathepsin B and elastase in orthotopic liver transplantation. Transplant Proc 23:1947, 1991.

25. Lie TS, R Seger, GS Hong, H Preisinger, K Ogawa: Protective effect of aprotinin on ischemic hepatocellular damage. Transplantation 48:396-399, 1989.

26. Morgan GR, PRC Harvey, SM Strasberg: Aprotinin for the pretreatment of liver allograft donors. Transplantation 49:1203, 1990.

27. Oldhafer KJ, W Schüttler, B Wiehe, J Hauss, R Pichlmayr: Treatment of preservation/reperfusion liver injury by the protease inhibitor aprotinin after cold ischemic storage. Transplant Proc 23:2380-2381, 1991 .

28. Wüthrich B, P Schmid, ER Schmid, M Tornic, SGO Johansson: IgE-mediated anaphylactic reaction to aprotinin during anaesthesia. Lancet 340:173-174, 1992. 